\title{
Selective localization of titanium dioxide nanoparticles at the interface and its effect on the impact toughness of poly(L-lactide)/poly(ether)urethane blends
}

\author{
H. Xiu, H. W. Bai, C. M. Huang, C. L. Xu, X. Y. Li, Q. Fu* \\ College of Polymer Science and Engineering, State Key Laboratory of Polymer Materials Engineering, Sichuan \\ University, 610065 Chengdu, P. R. China
}

Received 12 September 2012; accepted in revised form 10 November 2012

\begin{abstract}
Inorganic nanofillers are often added into polymer/elastomer blends as a third component to modify their performance. This work aims to clarify the role of interface-localized spherical nanoparticles in determining the impact toughness of polymer blends. The selective distribution of titanium dioxide $\left(\mathrm{TiO}_{2}\right)$ nanoparticles in poly(L-lactide)/poly(ether) urethane (PLLA/PU) blends was investigated by using scanning electron microscope. It is interesting to find that, regardless of the method of $\mathrm{TiO}_{2}$ introduction, nano- $\mathrm{TiO}_{2}$ particles are always selectively localized at the phase interface between PLLA and PU, leading to a significant improvement in notched Izod impact toughness. The moderately weakened interfacial adhesion induced by the interfacially-localized nano- $\mathrm{TiO}_{2}$ particles is believed to be the main reason for the largely enhanced impact toughness.
\end{abstract}

Keywords: biodegradable polymers, poly(L-lactide), mechanical properties, toughness, microstructure

\section{Introduction}

With increasing environmental concerns and decreasing petroleum resources, bio-based and biodegradable polymers have gained growing interest during recent years. As one of the most promising biodegradable polymers derived from renewable sources (e.g. corn and sugar beets), poly(L-lactide) (PLLA) exhibits great potential to replace traditional petroleum-based plastics (e.g. polypropylene (PP) and polystyrene (PS)) in a wide variety of applications due to its excellent transparency, good mechanical strength and easy processability [1-7]. Furthermore, similar to poly( $\varepsilon$-caprolactone) (PCL) $[8,9]$, PLLA has been already used in biomedical fields owing to its good biocompatibility $[2,5]$. However, the practical applications of PLLA are far from as widespread as expected because there are some drawbacks such as its inherent brittleness. Therefore, considerable efforts have been devoted to toughen PLLA [10-22]. Blending PLLA with other rubbery polymers, such as poly(ether)urethane (PU) elastomer [15], polyamide elastomer (PAE) [16], PCL $[17,18]$, poly(butylene succinate) (PBS) $[18,19]$, and ethylene-co-vinyl acetate (EVA) [20], provides a practical and economical way to improve the toughness of PLLA. Unfortunately, a substantial elastomer concentration of about $15-20 \mathrm{wt} \%$ is required to achieve effective toughening, which, in turn, leads to a significant deterioration in strength and stiffness $[15,17,20]$. To overcome this problem, inorganic nanofillers are often added into these blends as a third component to enhance the strength and stiffness, while maintaining or even further improving the obtained toughness [23-35].

Hitherto numerous studies have demonstrated that the key issue in achieving the optimal combination

\footnotetext{
${ }^{*}$ Corresponding author, e-mail: qiangfu@scu.edu.cn

(C) BME-PT
} 
of mechanical properties of polymer/elastomer/filler ternary nanocomposites is to tailor the phase morphology, especially the distribution of nanofillers in the matrix blends $[28,29]$. Generally, when nanofillers are introduced into an immiscible or partially miscible polymer blend, they often distribute heterogeneously, i.e. selectively dispersed in polymer matrix, in elastomer phase or at the interface between the two polymer phases, thus forming separated dispersion, rigid core-soft shell and soft core-rigid shell structures, respectively. In most cases, the formation of the rigid core-soft shell structure is found to be more favorable to achieve satisfactory toughness at lower elastomer concentration and, consequently, a good balance between toughness and stiffness as compared to the separated dispersion structure [23-25]. However, much less attention has been paid to the soft core-rigid shell structure possibly because it is difficult to realize the exclusive localization of nanofillers at the phase interface [33-37]. More importantly, to the best of our knowledge, so far very little information has been obtained about its effect on the mechanical properties of such nanocomposites. Excitedly, in the present work, we find that isotropic titanium dioxide $\left(\mathrm{TiO}_{2}\right)$ nanoparticles have a strong tendency to preferentially distribute at the interface of PLLA/PU blends with 'sea-island' morphology, forming a unique soft corerigid shell structure, i.e. PU particles are closely surrounded by a large amount of nano- $\mathrm{TiO}_{2}$ particles, which gives us a good chance to gain full insight into the role of the interface-localized nanoparticles in determining the performance of polymer blends, especially the impact toughness. To this aim, the relationship between microstructure and impact toughness of PLLA/PU/TiO ${ }_{2}$ nanocomposites is analyzed carefully and then several possible toughening mechanisms are discussed.

\section{Experimental}

\subsection{Materials}

PLLA (4032D, D-isomer content $=1.2-1.6 \%$ ) used as the matrix polymer was purchased from NatureWorks Co. Ltd, USA. It has a density of $1.25 \mathrm{~g} / \mathrm{cm}^{3}$, weight-averaged molecular weight $\left(M_{\mathrm{w}}\right)$ of $207 \mathrm{kDa}$, and polydispersity of 1.74 , respectively. PU (WHT1570, Yantai Wanhua Polyurethanes Co., Ltd, China) with a density of $1.21 \mathrm{~g} / \mathrm{cm}^{3}$ was selected as the impact modifier in this work. Nano-sized titanium dioxide $\left(\mathrm{TiO}_{2}\right.$, purity $>98 \%$, density $=4.25 \mathrm{~g} / \mathrm{cm}^{3}$, average particle size $=200 \mathrm{~nm}$ ) without any surface modification was produced by Chengdu Kelong Chemical Reagent Factory, China.

\subsection{Sample preparation}

$\mathrm{PLLA} / \mathrm{PU} / \mathrm{TiO}_{2}$ ternary nanocomposites were prepared by melt blending various amounts of $\mathrm{TiO}_{2}$ (0 25 wt\%) with PLLA/PU blend matrix (90:10 or $75: 25 \mathrm{w} / \mathrm{w}$ ) in a Haake mixer (XSS-300, USA) at a temperature of $190^{\circ} \mathrm{C}$ and rotor speed of $50 \mathrm{rpm}$ for $5 \mathrm{~min}$. In this case, $\mathrm{TiO}_{2}$, PLLA, and PU were loaded to the mixing chamber simultaneously. For comparison, PLLA/PU binary blends were blended under the same conditions. Specially, in order to investigate the effect of mixing procedure on the distribution of $\mathrm{TiO}_{2}$ in the nanocomposites, the other two blending procedures were also employed: blending of precompounded $\mathrm{PU} / \mathrm{TiO}_{2}$ or $\mathrm{PLLA} / \mathrm{TiO}_{2}$ with the second polymer (PLLA or PU) during a second blending step. All raw materials including PLLA, $\mathrm{PU}$ and $\mathrm{TiO}_{2}$ were dried under vacuum before using. To obtain standard specimens for mechanical testing, the obtained materials were then compression molded at $190^{\circ} \mathrm{C}$ for $5 \mathrm{~min}$ and then quenched to room temperature.

\subsection{Scanning electron microscopy (SEM)}

The phase morphologies of PLLA/PU blends with and without $\mathrm{TiO}_{2}$ were observed using an FEI Inspect $\mathrm{F}$ scanning electron microscope (SEM, USA) with an accelerating voltage of $5.0 \mathrm{kV}$. The specimens for the SEM observation were prepared by cryogenic fracture in liquid nitrogen. The impact fractured surfaces of the specimens after the impact testing were also observed by SEM.

\subsection{Surface energy measurement}

Contact angles measurement is a traditional and valid method to evaluate the surface energy of solids [38].The surface energy of a solid or a liquid and its dispersive and polar components can be calculated from the contact angle data by using Owens-Wendt method [39] (Equation (1) and (2)):

$$
\begin{aligned}
& \gamma_{\mathrm{s}}=\gamma_{\mathrm{s}}^{\mathrm{d}}+\gamma_{\mathrm{s}}^{\mathrm{p}} \\
& \gamma_{\mathrm{l}}(1+\cos \theta)=2 \sqrt{\gamma_{\mathrm{s}}^{\mathrm{d}} \gamma_{1}^{\mathrm{d}}}+2 \sqrt{\gamma_{\mathrm{s}}^{\mathrm{p}} \gamma_{1}^{\mathrm{p}}}
\end{aligned}
$$

where $\theta$ is the contact angle, $\gamma$ is the surface energy, subscripts ' $s$ ' and ' $l$ ' indicate solid and liquid, respec- 
tively, while superscripts ' $d$ ' and ' $p$ ' indicate the dispersive and polar components, respectively. Generally, in order to obtain the surface energy $\gamma_{\mathrm{s}}$ of the measured solid from Equations (1) and (2), at least two liquids, usually a polar and a nonpolar liquid, should be used. Here, two test liquids (i.e. distilled water $\left(\mathrm{H}_{2} \mathrm{O}\right)$ and diiodomethane $\left.\left(\mathrm{CH}_{2} \mathrm{I}_{2}\right)\right)$ were selected as widely reported in the literature $[28,40]$. The values of surface energy of the two test liquids are $\gamma^{\mathrm{p}}=50.7 \mathrm{mN} / \mathrm{m}$ and $\gamma^{\mathrm{d}}=22.1 \mathrm{mN} / \mathrm{m}$ for $\mathrm{H}_{2} \mathrm{O}$, and $\gamma^{\mathrm{p}}=6.7 \mathrm{mN} / \mathrm{m}$ and $\gamma^{\mathrm{d}}=44.1 \mathrm{mN} / \mathrm{m}$ for $\mathrm{CH}_{2} \mathrm{I}_{2}$ [28].

The contact angle tests were conducted on a DSA100 apparatus (Krüss GmbH, Germany) based on the sessile drop method, i.e. depositing a drop of test liquid onto the sample surface. At least six replicates were performed for each sample to ensure the reproducibility of the measured data. Prior to the measurements, $\mathrm{TiO}_{2}$ powders were compression molded by using a home-made metal mold at room temperature under a pressure of $15 \mathrm{MPa}$, while PLLA and PU specimens were compression molded at $190^{\circ} \mathrm{C}$ for $5 \mathrm{~min}$ and then quenched to $25^{\circ} \mathrm{C}$.

\subsection{Mechanical testing}

The notched Izod impact strength was measured using an impact tester (XJU-5.5, China), according to ISO180/179 standard. Pendulum impact velocity is $3.5 \mathrm{~m} / \mathrm{s}$. Tensile testing was performed with a SANS universal tensile testing machine (China) at a cross-head speed of $5 \mathrm{~mm} / \mathrm{min}$, according to ISO 527-3 standard. For each sample, the measurements were carried out at room temperature $\left(23^{\circ} \mathrm{C}\right)$ and the results obtained were averaged at least five specimens.

\subsection{Differential scanning calorimetry (DSC)}

The degree of crystallinity $\left(X_{\mathrm{c}}\right)$ of the PLLA matrix in the compression molded samples was evaluated using differential scanning calorimetry (DSC, PerkinElmer pyris-1, USA) in a dry nitrogen atmosphere. For each measurement, about $5 \mathrm{mg}$ of the sample was directly heated from 0 to $200^{\circ} \mathrm{C}$ at a heating rate of $10^{\circ} \mathrm{C} / \mathrm{min}$. The value of were determined using the most commonly used Equation (3) [21, 22, 41]:

$X_{\mathrm{c}}=\frac{\Delta H_{\mathrm{m}}-\Delta H_{\mathrm{c}}}{w_{\mathrm{f}} \Delta H_{\mathrm{m}}^{0}} \cdot 100 \%$ where $\Delta H_{\mathrm{m}}$ and $\Delta H_{\mathrm{c}}$ are the enthalpies of melting and cold crystallization, respectively; $w_{\mathrm{f}}$ is the weight percent of the PLLA matrix, and $\Delta H_{\mathrm{m}}^{0}$ is the melting enthalpy of completely crystalline PLLA (93.7 J/g [42]).

\section{Results and discussion \\ 3.1. Phase morphology and selective localization of nano- $\mathrm{TiO}_{2}$ particles}

In order to elucidate the microstructure and morphology of PLLA/PU blends with and without $\mathrm{TiO}_{2}$, SEM experiment was carried out and the results are shown in Figure 1. Obviously, all samples exhibit typical 'sea-island' morphologies, where discrete PU spherical domains are uniformly dispersed in the PLLA matrix. Unexpectedly, with the introduction of $15 \mathrm{phr}$ nano- $\mathrm{TiO}_{2}$ particles into the blend of PLLA/10PU, the size of the PU domains increases slightly (Figure 1b). This result is opposite to that usually seen in polymer blends filled with other nanofillers, such as silicon dioxide $\left(\mathrm{SiO}_{2}\right)$, clay and multi-walled carbon nanotubes (MWCNTs), where the size of dispersed-phase domains decreases significantly with adding small amounts of nanofillers [43-45]. Recently, Cai et al. [46] confirmed that morphology evolution of immiscible polymer blends is strongly dominated by the self-agglomerating pattern of nanoparticles in polymer melts. An increase in the size of PA6 domains is observed as high loading of nano- $\mathrm{TiO}_{2}$ (e.g. $25 \mathrm{phr}$ ) is added into $\mathrm{PS} / 30 \mathrm{PA} 6$ blend due to its unique self-agglomerating pattern completely different from other nanofillers. Similarly, the increased size of the PU domains may be associated with the unique self-agglomerating pattern of the $\mathrm{TiO}_{2}$, which needs further investigation in our future work. Very interestingly, almost all nano- $\mathrm{TiO}_{2}$ particles are selectively located at the phase interface between PLLA and PU in PLLA/ $10 \mathrm{PU} / 15 \mathrm{TiO}_{2}$ ternary nanocomposite, which can be observed more clearly in the ternary samples containing relatively high content of PU, such as PLLA/ $25 \mathrm{PU} / 15 \mathrm{TiO}_{2}$ nanocomposite (Figure 1c). In this case, spherical PU domains are surrounded by a large number of nano- $\mathrm{TiO}_{2}$ particles, forming a special soft core-rigid shell structure in the PLLA matrix. More interestingly, the distribution of nano- $\mathrm{TiO}_{2}$ particles in the obtained PLLA/PU/TiO 2 nanocomposites is independent on the method of $\mathrm{TiO}_{2}$ introduction, as shown in Figure 2. In all cases, nano$\mathrm{TiO}_{2}$ particles are mainly located at the interface 


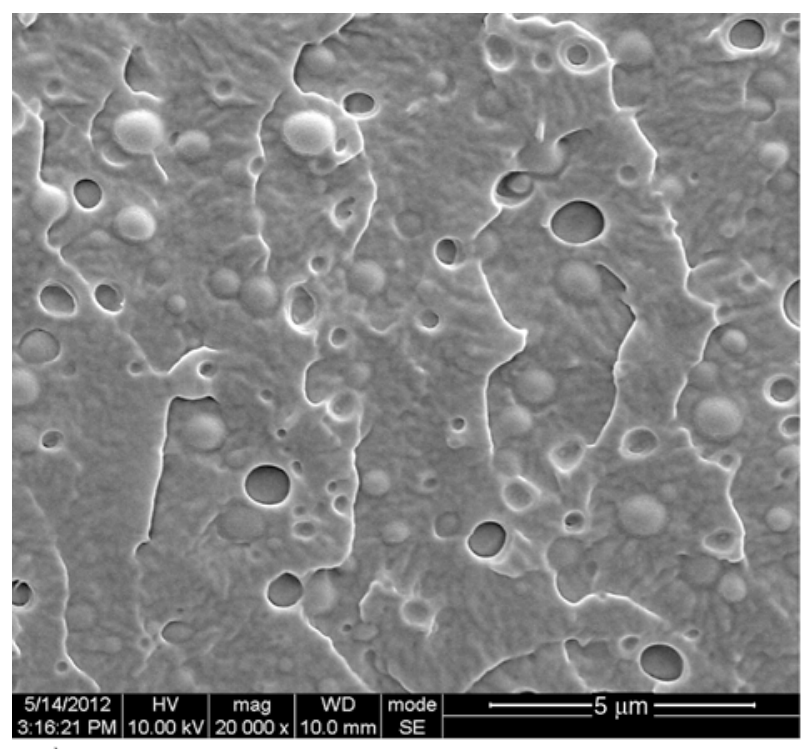

a)

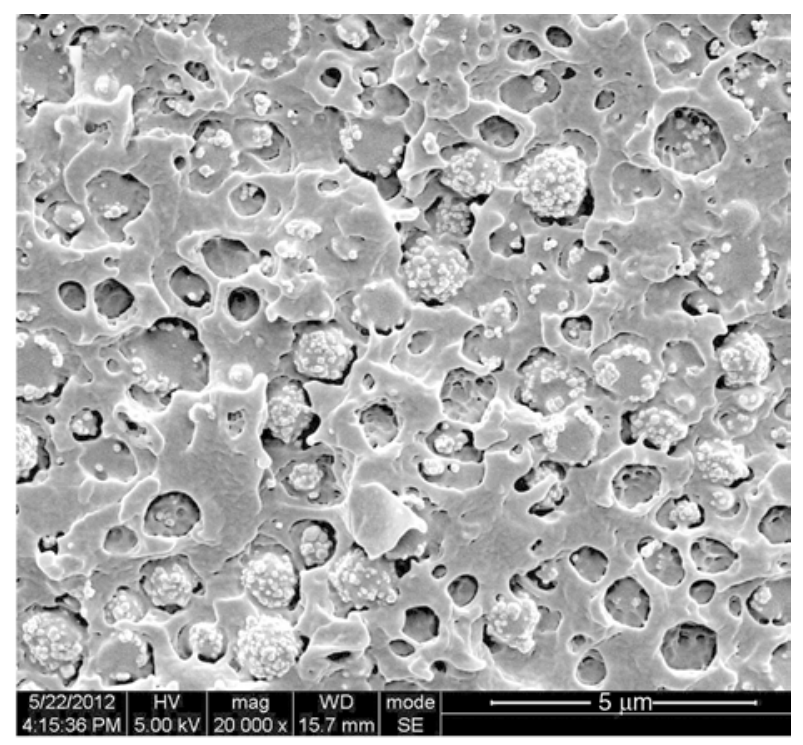

b)

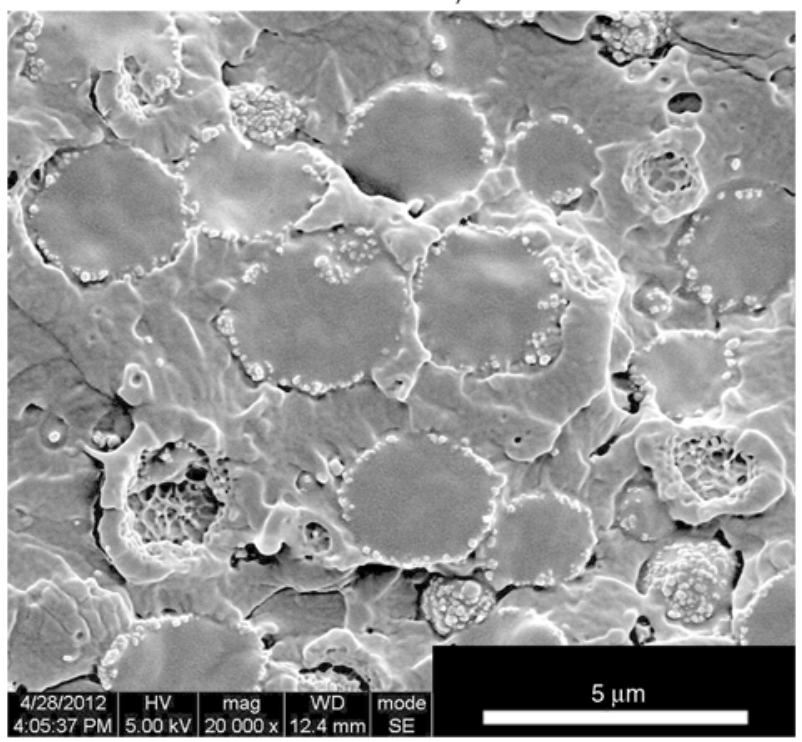

c)

Figure 1. SEM micrographs of the cryofractured surfaces of PLLA/PU blends with and without $\mathrm{TiO}_{2}$ : (a) PLLA/10PU, (b) PLLA/10PU/15 $\mathrm{TiO}_{2}$, and (c) PLLA/25PU/15 TiO 2

and almost no nano- $\mathrm{TiO}_{2}$ particles can be found in the two blend components (PLLA and PU), suggesting that the nano- $\mathrm{TiO}_{2}$ particles should be thermodynamically driven into the phase interface during mixing process. This conclusion can be further confirmed by theoretical calculation using the wetting coefficient $\omega_{\mathrm{a}}$ defined by Equation (4) [47]:

$\omega_{\mathrm{a}}=\frac{\gamma_{\mathrm{PLLA}_{-\mathrm{TiO}_{2}}-\gamma_{\mathrm{PU}-\mathrm{TiO}_{2}}}}{\gamma_{\mathrm{PLLA}-\mathrm{PU}}}$

where $\gamma_{\text {PLLA-TiO }_{2}}, \gamma_{\text {PU-TiO }_{2}}$, and $\gamma_{\text {PLLA-PU }}$ are the interfacial energies between PLLA and $\mathrm{TiO}_{2}$, between $\mathrm{PU}$ and $\mathrm{TiO}_{2}$, between PLLA and PU, respectively. $\omega_{\mathrm{a}}$ has been widely used to predict the thermodynamic equilibrium distribution of nanofillers in polymer blends $[25,40]$. Generally, for $\omega_{\mathrm{a}}>1, \mathrm{TiO}_{2}$ particles are only found in $\mathrm{PU}$; for $\omega_{\mathrm{a}}<-1, \mathrm{TiO}_{2}$ particles are present only in PLLA and for $-1<$ $\omega_{\mathrm{a}}<1, \mathrm{TiO}_{2}$ particles are selectively located at the interface between PLLA and PU.

The interfacial energy can be obtained from surface energies of the corresponding components and their dispersive and polar parts, based on the two most commonly used methods, i.e. harmonic-mean Equation (5) and geometric-mean Equation (6) [38]:

Harmonic-mean equation:

$$
\gamma_{12}=\gamma_{1}+\gamma_{2}-4\left(\frac{\gamma_{1}^{\mathrm{d}} \gamma_{2}^{\mathrm{d}}}{\gamma_{1}^{\mathrm{d}}+\gamma_{2}^{\mathrm{d}}}+\frac{\gamma_{1}^{\mathrm{p}} \gamma_{2}^{\mathrm{p}}}{\gamma_{1}^{\mathrm{p}}+\gamma_{2}^{\mathrm{p}}}\right)
$$

Geometric-mean equation:

$\gamma_{12}=\gamma_{1}+\gamma_{2}-2\left(\sqrt{\gamma_{1}^{\mathrm{d}} \gamma_{2}^{\mathrm{d}}}+\sqrt{\gamma_{1}^{\mathrm{p}} \gamma_{2}^{\mathrm{p}}}\right)$ 


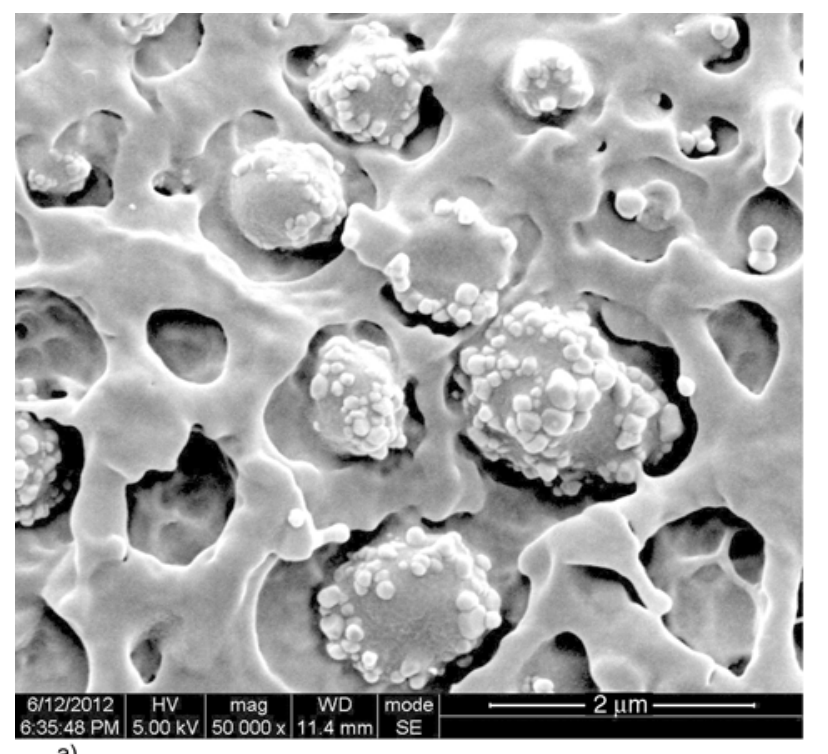

a)

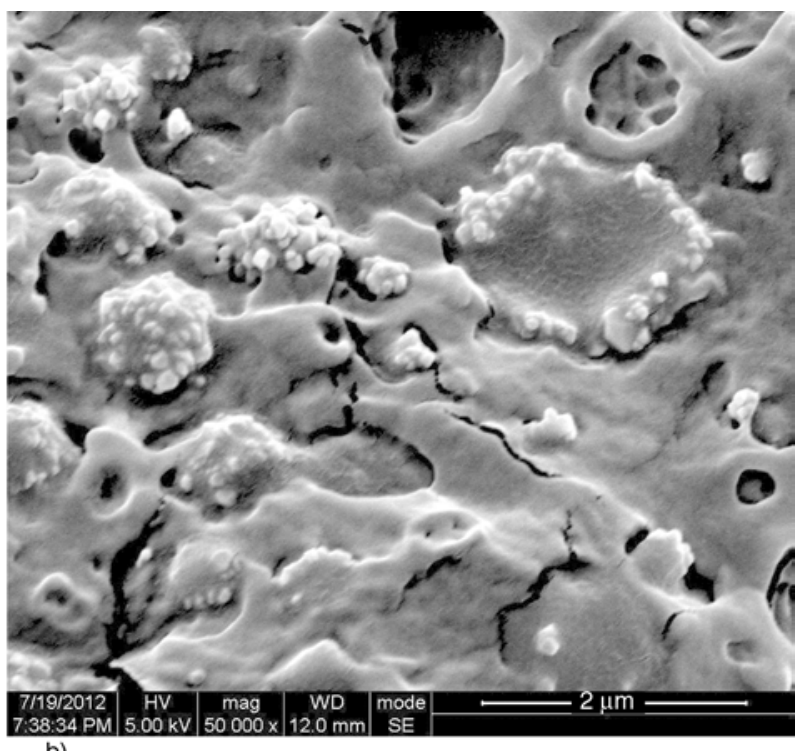

b)

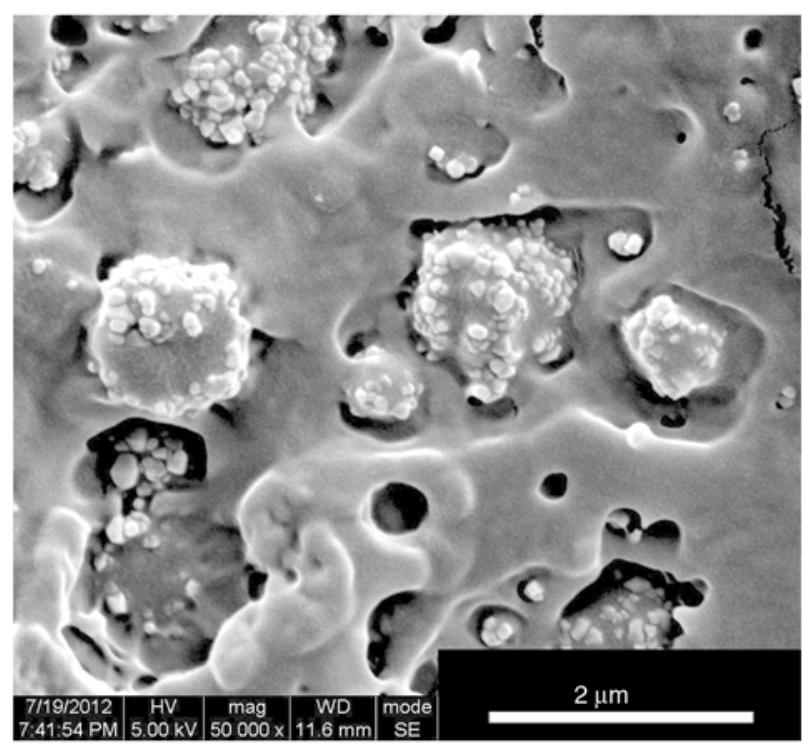

c)

Figure 2. SEM micrographs of the cryofractured surfaces of PLLA/10PU/15 $\mathrm{TiO}_{2}$ composites prepared by different blending procedures: (a) direct blending of all three components, (b) blending of premixed $\mathrm{PU} / \mathrm{TiO}_{2}$ with PLLA, and (c) blending of premixed PLLA/TiO 2 with $\mathrm{PU}$

Table 1. The measured contact angles and calculated surface energy data of PLLA, PU and $\mathrm{TiO}_{2}$

\begin{tabular}{|l|c|c|c|c|c|}
\hline \multirow{2}{*}{ Sample } & \multicolumn{2}{|c|}{ Contact angles $\left[{ }^{\circ}\right]$} & \multicolumn{3}{|c|}{ Surface energy [mN/m] } \\
\cline { 2 - 6 } & $\mathbf{H}_{\mathbf{2}} \mathbf{O}$ & $\mathbf{C H}_{\mathbf{2}} \mathbf{I}_{\mathbf{2}}$ & $\boldsymbol{\gamma}$ & $\boldsymbol{\gamma}^{\mathbf{d}}$ & $\boldsymbol{\gamma}^{\mathbf{p}}$ \\
\hline PLLA & 78.5 & 37.7 & 47.74 & 38.37 & 9.37 \\
\hline $\mathrm{PU}$ & 78.1 & 55.2 & 41.69 & 30.36 & 11.33 \\
\hline $\mathrm{TiO}_{2}$ & 19.7 & 10.1 & 80.70 & 46.40 & 34.30 \\
\hline
\end{tabular}

where $\gamma_{\mathrm{i}}$ is the surface energy of component $i, \gamma_{\mathrm{i}}^{\mathrm{d}}$ and $\gamma_{\mathrm{i}}^{\mathrm{p}}$ are the dispersive and polar contributions to the surface energy of component $i$, respectively.

In this work, the values of surface energies were calculated from the contact angle data by using Equation (1) and Equation (2) and the results are summarized in Table 1 . The values of interfacial
Table 2. Interfacial tensions and wetting coefficient as calculated using harmonic-mean and geometric-mean equations

\begin{tabular}{|l|c|c|}
\hline $\begin{array}{c}\text { Component } \\
\text { couple }\end{array}$ & $\begin{array}{c}\text { Based on harmonic- } \\
\text { mean equation } \\
\text { [mN/m] }\end{array}$ & $\begin{array}{c}\text { Based on geometric- } \\
\text { mean equation } \\
\text { [m N/m] }\end{array}$ \\
\hline $\mathrm{PLLA} / \mathrm{PU}$ & 1.06 & 0.56 \\
\hline $\mathrm{PLLA} / \mathrm{TiO}_{2}$ & 15.00 & 8.20 \\
\hline $\mathrm{PU} / \mathrm{TiO}_{2}$ & 14.91 & 7.89 \\
\hline$\omega_{\mathrm{a}}$ & 0.08 & 0.55 \\
\hline
\end{tabular}

energies and are listed in Table 2. As expected, the value of is 0.08 based on Harmonic-mean equation, and 0.55 based on Geometric-mean equation, indicating that the state of thermodynamic equilibrium distribution of nano- $\mathrm{TiO}_{2}$ particles should be selec- 
tively concentrated at the interface between PLLA and PU.

\subsection{Mechanical properties}

As discussed in the introduction, the distribution of nanofillers plays a decisive role in controlling the performance of polymer/elastomer/filler nanocomposites. In order to know the effect of such interfacially-localized nano- $\mathrm{TiO}_{2}$ particles on the mechanical properties of PLLA/PU blends, notched Izod impact toughness and tensile properties were evaluated. Figure 3 shows the impact strength of PLLA

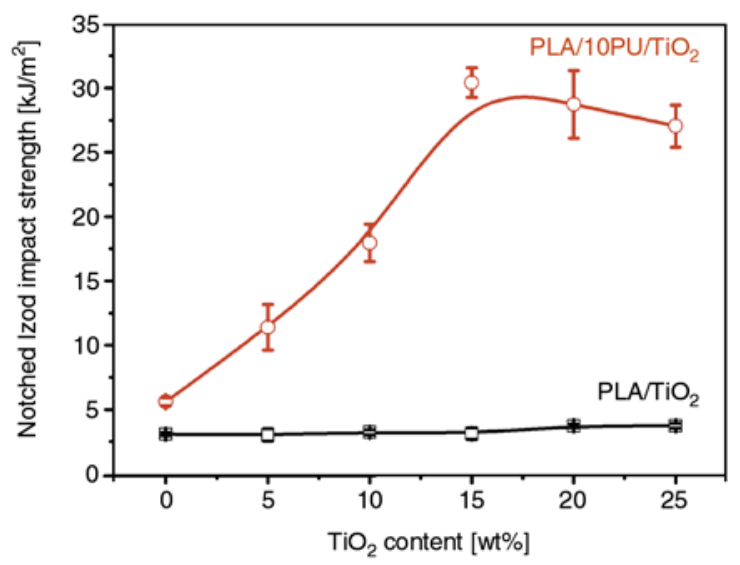

Figure 3. Notched Izod impact strength of PLLA and PLLA/10PU blends with various amounts of $\mathrm{TiO}_{2}$

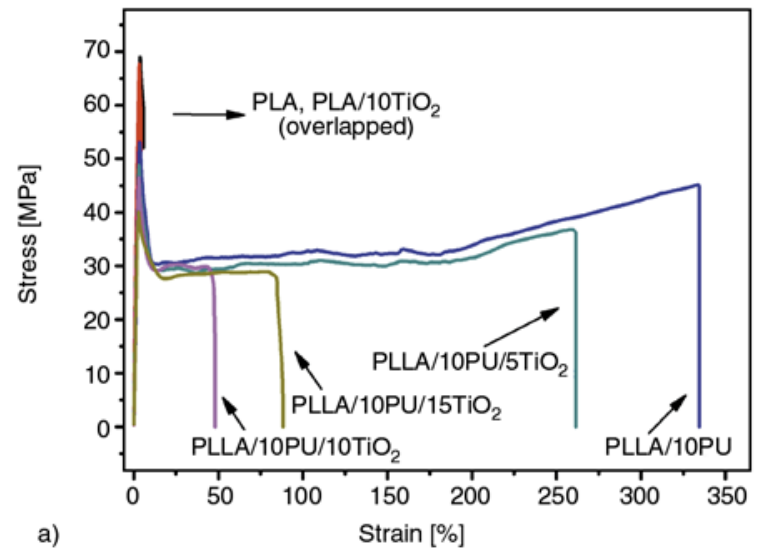

and PLLA/10PU blends as a function of nano- $\mathrm{TiO}_{2}$ content. It is very interesting to observe that, although no obvious toughening effect on PLLA matrix can be obtained by only adding low content (e.g. $10 \mathrm{wt} \%$ ) of nano- $\mathrm{TiO}_{2}$ or $\mathrm{PU}$, the presence of nano- $\mathrm{TiO}_{2}$ particles at the interface gives rise to a largely improved impact toughness of PLLA/10PU blend. For example, the impact strength of PLLA/10PU blend increases remarkably from 5.61 to $30.41 \mathrm{~kJ} / \mathrm{m}^{2}$ with increasing nano- $\mathrm{TiO}_{2}$ content up to $15 \mathrm{phr}$. This indicates that realizing selective distribution of nano$\mathrm{TiO}_{2}$ particles at the interface is an effective method to toughen PLLA/PU blends. Meanwhile, it should be noted that there is a saturation of the toughening effect. With further increasing nano- $\mathrm{TiO}_{2}$ content, the high-concentration (e.g. $25 \mathrm{phr}$ ) nano- $\mathrm{TiO}_{2}$ induces a slight decrease of impact toughness due to the serious aggregation of nano- $\mathrm{TiO}_{2}$ particles in this condition (as discussed below). Unfortunately, the nano- $\mathrm{TiO}_{2}$ induces dramatic improvement in the impact toughness, but evident deterioration in tensile strength and elongation at break, as can be observed in Figure 4 and Table 3. This can be explained as follows. On one hand, the existence of large amounts of nano- $\mathrm{TiO}_{2}$ around $\mathrm{PU}$ domains can lead to a moderate increase in the effective vol-

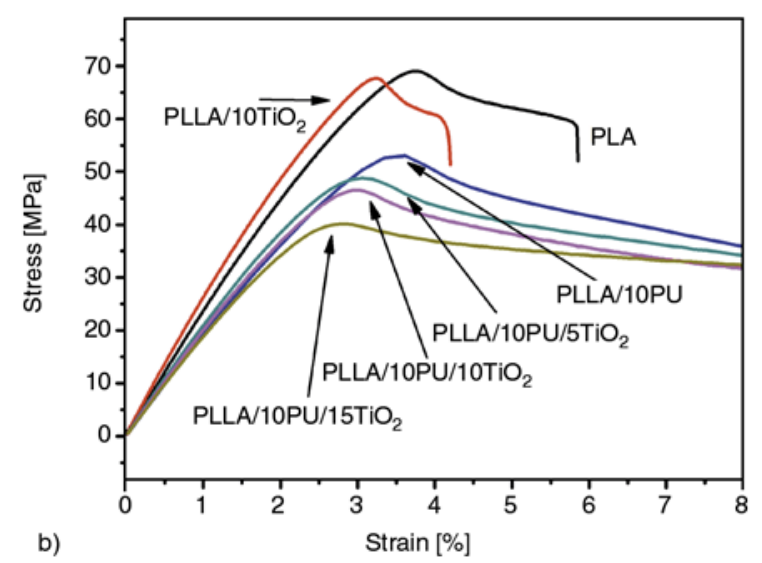

Figure 4. (a) Stress-strain curves of PLLA and PLLA/10PU blends with various amounts of $\mathrm{TiO}_{2}$, and (b) enlarged part of the curves

Table 3. Mechanical properties of PLLA and PLLA/10PU blends with various amounts of $\mathrm{TiO}_{2}$

\begin{tabular}{|c|c|c|c|c|}
\hline Sample & $\begin{array}{l}\text { Yield stress } \\
\text { [MPa] }\end{array}$ & $\begin{array}{l}\text { Modulus } \\
\text { MPa[ }\end{array}$ & $\begin{array}{c}\text { Elongation at break } \\
{[\%]}\end{array}$ & $\begin{array}{c}\text { Notched impact strength } \\
{\left[\mathrm{kJ} / \mathrm{m}^{2}\right]}\end{array}$ \\
\hline PLLA & $68.36 \pm 0.67$ & $2452.80 \pm 29.69$ & $5.67 \pm 0.18$ & $3.10 \pm 0.12$ \\
\hline PLLA/10 $10 \mathrm{TiO}_{2}$ & $67.21 \pm 0.98$ & $2730.10 \pm 22.65$ & $4.17 \pm 0.07$ & $3.23 \pm 0.23$ \\
\hline PLLA/10PU & $53.35 \pm 0.63$ & $1946.75 \pm 59.75$ & $313.42 \pm 32.81$ & $5.61 \pm 0.32$ \\
\hline PLLA/10PU/5 $/ \mathrm{TiO}_{2}$ & $49.02 \pm 0.36$ & $2143.17 \pm 62.43$ & $235.37 \pm 59.77$ & $11.39 \pm 1.78$ \\
\hline PLLA/10PU/10 $\mathrm{TiO}_{2}$ & $47.04 \pm 0.58$ & $2099.11 \pm 23.87$ & $41.24 \pm 20.00$ & $17.95 \pm 1.44$ \\
\hline PLLA/10PU/15 $\mathrm{TiO}_{2}$ & $41.21 \pm 0.68$ & $1969.38 \pm 20.90$ & $69.04 \pm 37.04$ & $30.41 \pm 0.16$ \\
\hline PLLA/15PU & $46.87 \pm 0.10$ & $1939.78 \pm 27.39$ & $294.09 \pm 29.11$ & $23.19 \pm 2.93$ \\
\hline
\end{tabular}


ume of PU dispersed phase. One the other hand, unlike bridge effect of MWCNTs with high aspect ratio, the interfacially-localized nano- $\mathrm{TiO}_{2}$ particles are most likely to weaken the interfacial bonding strength between PLLA and PU because of the shielding effect, thus promoting debonding of PU domains from PLLA matrix during deformation. Both factors are believed to contribute to the substantially reduced tensile strength, based on the fact that, although the true volume fraction of PU phase $(18.4 \%)$ in PLLA/15PU blend is higher than the effective volume fraction of PU phase (14.9\%) in PLLA/10PU/15 $\mathrm{TiO}_{2}$ nanocomposite, the former sample exhibits a much higher tensile strength as compared with the latter one (Table 3). With regard to the remarkably decreased extensibility, undoubtedly, the latter factor is the main reason. Furthermore, one thing should be stressed that tensile testing and notched Izod impact testing were carried out at remarkably different test speeds. Thus, the materials are most likely to exhibit different mechanical responses when they are subjected to different loading conditions. For the tensile testing, the tensile speed is only $5 \mathrm{~mm} / \mathrm{min}$, indicating a quasi-static loading condition. In this case, the presence of nano- $-\mathrm{TiO}_{2}$ particles at the interface is unfavorable to the stress transferring between PLLA and PCL because of the reduced interfacial adhesion, thus giving rise to the notably reduced extensibility. However, for the notched Izod impact testing, the impact speed is as high as $3.5 \mathrm{~m} / \mathrm{s}$, indicating a dynamic loading condition. In this case, the interfacial-localized nano- $\mathrm{TiO}_{2}$ particles seem to be favorable to the toughening.

\subsection{Toughening mechanism}

To make clear the role of the interfacial-localized nano- $\mathrm{TiO}_{2}$ particles in the toughening of PLLA/PU blends, the impact fractured surfaces of PLLA/ 10PU blends with and without $\mathrm{TiO}_{2}$ particles were characterized by SEM, and the results are given in Figure 5. Clearly, the blank PLLA/10PU blend exhibits a typical brittle failure. The fractured surface is very smooth and no evident deformation of PLLA matrix appears (Figure 5a). This suggests that fast crack propagation occurs during impact fracture process. In contrast, after adding $10-15 \mathrm{phr}$ $\mathrm{TiO}_{2}$, many fibrils as a result of crazing of PLLA matrix can be clearly observed on the whole surface (Figure $5 \mathrm{~b}$ and $5 \mathrm{c}$ ), indicating that the interfacial- localized nano- $\mathrm{TiO}_{2}$ particles effectively facilitate the deformation of PLLA matrix through crazing mechanism. Moreover, these highly stretched fibrils can prevent the crack initiation and propagation, allowing for a considerable plastic deformation to develop [48]. As a result, substantial energy is consumed, leading to the high impact toughness. Now it is logical to ask how the nano- $\mathrm{TiO}_{2}$ particles induce the stable crazes in PLLA matrix. In fact, it has been widely accepted that the role of elastomer in toughening polymers is mainly associated with the cavitation of elastomer particles and the cavitation caused by interfacial debonding can promote energy dissipation through relaxing the locally triaxial stress that favors brittle failure [49-51]. Here, since spherical nano- $\mathrm{TiO}_{2}$ particles located at the interface can weaken the interfacial adhesion between PLLA matrix and PU dispersed phase to a certain extent (evidenced by the decreased tensile strength as discussed above), the interfacial debonding and, consequently, the plastic deformation of PLLA matrix become easier to be triggered as compared to the blank PLLA/PU blends. This mechanism has been successfully used to explain the reason for the enhanced toughness of epoxy/acrylic rubber blends induced by the interfacial-localized clay [52]. On the other hand, Shi et al. [35] have demonstrated that the introduction of interfacelocalized MWCNTs causes a decrease in the impact strength of PLLA/EVA blends, suggesting that the enhanced interfacial adhesion seems to be unfavorable to the toughening of PLLA/elastomer blends. Furthermore, by considering that the impact strength of PLLA $/ 10 \mathrm{PU} / 15 \mathrm{TiO}_{2}$ nanocomposite with a lower effective volume fraction of PU phase (14.9\%) is much higher than PLLA/15PU blend with a higher true volume fraction of PU phase (18.4\%) (Table 3), we believe that the increase in the effective volume fraction of PU phase has little influence on the improvement in the impact toughness. Therefore, the largely enhanced impact toughness of PLLA/ PU blends induced by the interfacial-localized nano- $\mathrm{TiO}_{2}$ is mainly attributed to the moderately reduced interfacial debonding. Most importantly, it should be noted that appropriate concentration of $\mathrm{TiO}_{2}$ is the prerequisite to obtain the blends with good impact toughness. At high concentrations (e.g. $25 \mathrm{phr}$ ), some of nano- $\mathrm{TiO}_{2}$ particles aggregate together and form large aggregates at the phase interface and, subsequent, only small amounts of 


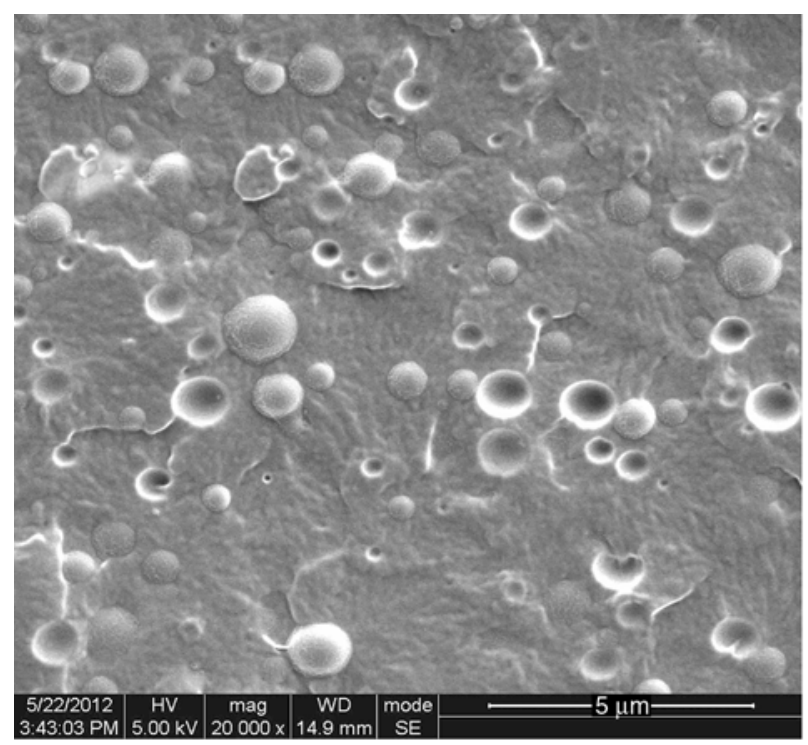

a)

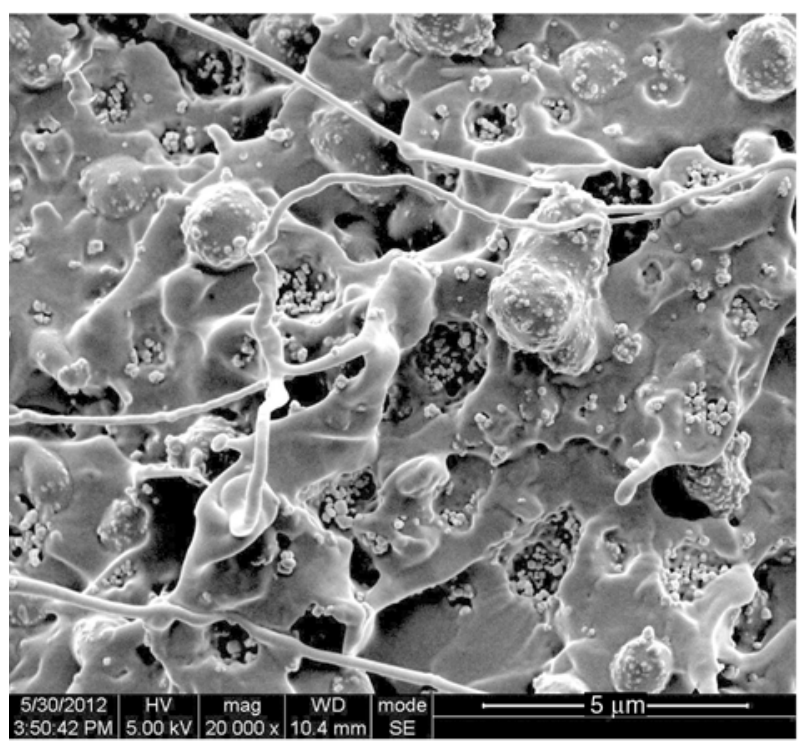

c)

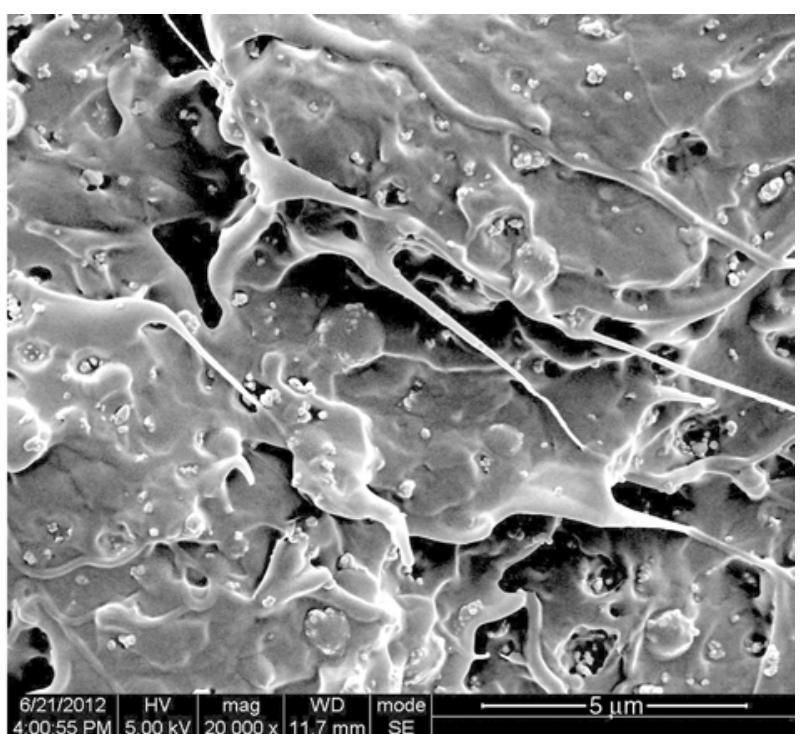

b)

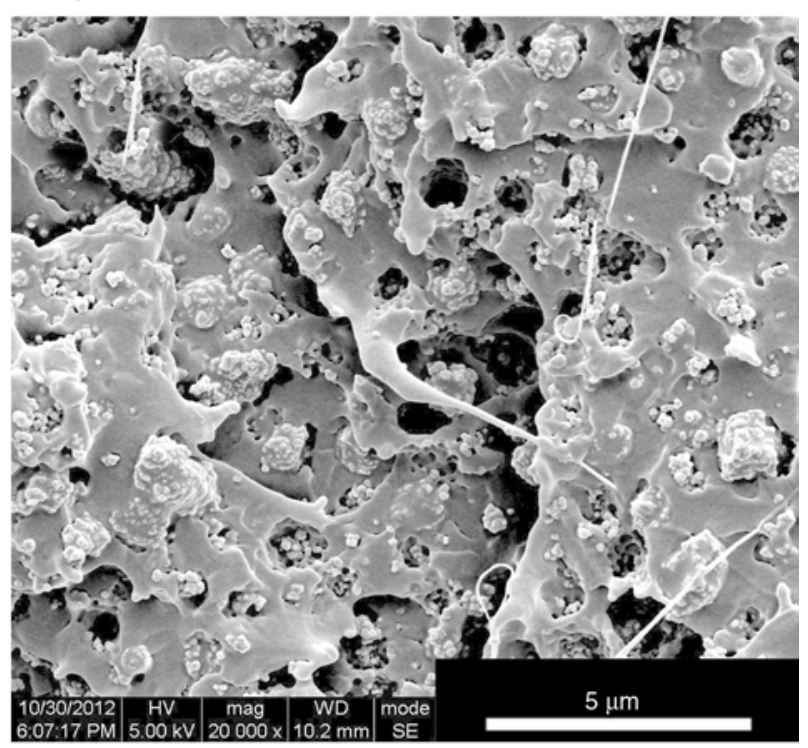

Figure 5. SEM micrographs of impact fractured surfaces of PLLA/10PU blends with and without $\mathrm{TiO}_{2}$ : (a) PLLA/10PU, (b) $\mathrm{PLLA} / 10 \mathrm{PU} / 10 \mathrm{TiO}_{2}$, (c) $\mathrm{PLLA} / 10 \mathrm{PU} / 15 \mathrm{TiO}_{2}$, and (d) $\mathrm{PLLA} / 10 \mathrm{PU} / 25 \mathrm{TiO}_{2}$

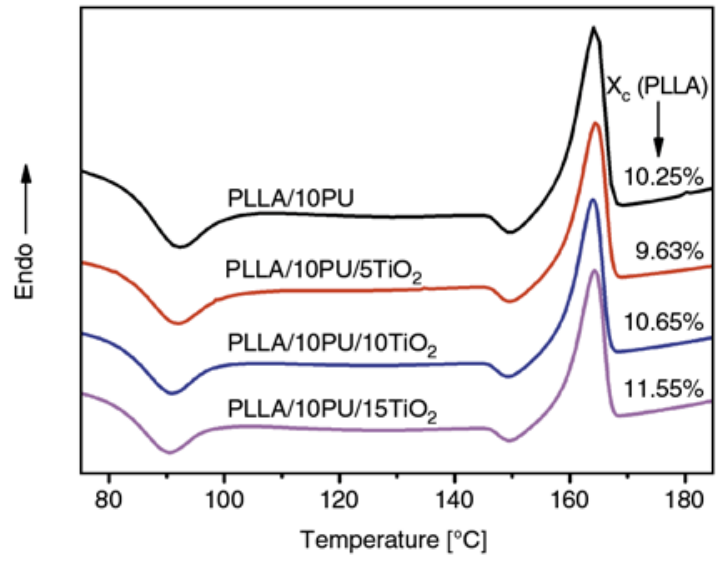

Figure 6. DSC heating curves of PLLA/10PU blends with various amounts of $\mathrm{TiO}_{2}$ highly stretched fibrils and less evident matrix deformation can be observed on the impact fractured surface (Figure 5d). This observation is well consistent with the deteriorated impact toughness of the blends with high-concentration $\mathrm{TiO}_{2}$ as mentioned above.

In addition, our previous work has shown that the crystallinity of PLLA matrix may influence the impact toughness of PLLA/elastomer blend [53]. However, it can be disregarded completely in this work. All the samples present the same low level of the PLLA matrix crystallinity $(\sim 10 \%)$, as displayed in Figure 6. 


\section{Conclusions}

In this work, PLLA/PU/TiO 2 ternary nanocomposites were prepared by three different mixing procedures. Regardless of the method of $\mathrm{TiO}_{2}$ introduction, almost all nano- $\mathrm{TiO}_{2}$ particles are located around spherical PU domains, forming a unique soft core-rigid shell structure in the PLLA matrix. The results show that the addition of nano- $\mathrm{TiO}_{2}$ leads to a largely enhanced impact toughness of PLLA/PU blend mainly due to the weakened interfacial debonding in the presence of the interfaciallocalized nano- $\mathrm{TiO}_{2}$ particles. During the impact process, nano- $\mathrm{TiO}_{2}$ particles induce interfacial debonding, promoting the plastic deformation of PLLA matrix through crazing rather than crack, thus dissipating large amounts of energy. This work not only provides a simple and effective method to largely improve the impact toughness of polymer blends, but also gives a comprehensive understanding of the role of interfacial-localized spherical

\section{Acknowledgements}

We would like to express our great thanks to the National Natural Science Foundation of China (50903048 and 51121001) for Financial Support.

\section{References}

[1] Auras R., Harte B., Selke S.: An overview of polylactides as packaging materials. Macromolecular Bioscience, 4, 835-864 (2004). DOI: $10.1002 / \mathrm{mabi} .200400043$

[2] Nampoothiri K. M., Nair N., R., John R. P.: An overview of the recent developments in polylactide (PLA) research. Bioresource Technology, 101, 84938501 (2010).

DOI: $10.1016 /$ j.biortech.2010.05.092

[3] Gross R. A., Kalra B.: Biodegradable polymers for the environment. Science, 297, 803-807 (2002).

DOI: $10.1126 /$ science.297.5582.803

[4] del Valle L. J., Díaz A., Royo M., Rodríguez-Galán A., Puiggalí J.: Biodegradable polyesters reinforced with triclosan loaded polylactide micro/nanofibers: Properties, release and biocompatibility. Express Polymer Letters, 6, 266-282 (2012).

DOI: $10.3144 /$ expresspolymlett.2012.30

[5] Rasal R. M., Janorkar A. V., Hirt D. E.: Poly(lactic acid) modifications. Progress in Polymer Science, 35, 338-356 (2010).

DOI: $10.1016 /$ j.progpolymsci.2009.12.003

[6] Drumright R. E., Gruber P. R., Henton D. E.: Polylactic acid technology. Advanced Materials, 12, 18411846 (2000).

DOI: $10.1002 / 1521-4095(200012) 12: 23<1841:: A I D-$ ADMA1841>3.0.CO;2-E
[7] Lim L-T., Auras R., Rubino M.: Processing technologies for poly(lactic acid). Progress in Polymer Science, 33, 820-852 (2008).

DOI: $10.1016 / j . p r o g p o l y m s c i .2008 .05 .004$

[8] De Santis R., Catauro M., Di Silvio L., Manto L., Raucci M., Ambrosio L., Nicolais L.: Effects of polymer amount and processing conditions on the in vitro behaviour of hybrid titanium dioxide/polycaprolactone composites. Biomaterials, 28, 2801-2809 (2007). DOI: 10.1016/j.biomaterials.2007.02.014

[9] Russo T., Gloria A., D-Antò V., D’Amora U., Ametrano G., Bollino F., De Santis R., Ausanio G., Catauro M., Rengo S., Ambrosio L.: Poly( $\varepsilon$-caprolactone) reinforced with sol-gel synthesized organic-inorganic hybrid fillers as composite substrates for tissue engineering. Journal of Applied Biomaterials and Biomechanics, 8, 146-152 (2010).

DOI: $10.5301 /$ jabb.2010.6094

[10] Liu H., Zhang J.: Research progress in toughening modification of poly(lactic acid). Journal of Polymer Science Part B: Polymer Physics, 49, 1051-1083 (2011).

DOI: $10.1002 /$ polb.22283

[11] Martin O., Avérous L.: Poly(lactic acid): Plasticization and properties of biodegradable multiphase systems. Polymer, 42, 6209-6219 (2001). DOI: 10.1016/S0032-3861(01)00086-6

[12] Kulinski Z., Piorkowska E., Gadzinowska K., Stasiak M.: Plasticization of poly(L-lactide) with poly(propylene glycol). Biomacromolecules, 7, 2128-2135 (2006). DOI: $10.1021 / \mathrm{bm} 060089 \mathrm{~m}$

[13] Ljungberg N., Wesslén B.: Preparation and properties of plasticized poly(lactic acid) films. Biomacromolecules, 6, 1789-1796 (2005).

DOI: $10.1021 / \mathrm{bm} 050098 \mathrm{f}$

[14] Ljungberg N., Wesslén B.: Tributyl citrate oligomers as plasticizers for poly(lactic acid): Thermo-mechanical film properties and aging. Polymer, 44, 7679-7688 (2003).

DOI: 10.1016/j.polymer.2003.09.055

[15] Li Y., Shimizu H.: Toughening of polylactide by melt blending with a biodegradable poly(ether)urethane elastomer. Macromolecular Bioscience, 7, 921-928 (2007).

DOI: $10.1002 /$ mabi.200700027

[16] Zhang W., Chen L., Zhang Y.: Surprising shape-memory effect of polylactide resulted from toughening by polyamide elastomer. Polymer, 50, 1311-1315 (2009). DOI: 10.1016/j.polymer.2009.01.032

[17] López-Rodríguez M., López-Arraiza A., Meaurio E., Sarasua J. R.: Crystallization, morphology, and mechanical behavior of polylactide/poly( $\varepsilon$-caprolactone) blends. Polymer Engineering and Science, 46, 1299-1308 (2006).

DOI: 10.1002/pen.20609 
[18] Vilay V., Mariatti M., Ahmad Z., Pasomsouk K., Todo M.: Characterization of the mechanical and thermal properties and morphological behavior of biodegradable poly(L-lactide)/poly( $\varepsilon$-caprolactone) and poly(Llactide)/poly(butylene succinate-co-L-lactate) polymeric blends. Journal of Applied Polymer Science, 114, 1784-1792 (2009).

DOI: 10.1002/app.30683

[19] Shibata M., Inoue Y., Miyoshi M.: Mechanical properties, morphology, and crystallization behavior of blends of poly(L-lactide) with poly(butylene succinate-co-L-lactate) and poly(butylene succinate). Polymer, 47, 3557-3564 (2006).

DOI: $10.1016 /$ j.polymer.2006.03.065

[20] Yoon J-S., Oh S-H., Kim M-N., Chin I-J., Kim Y-H.: Thermal and mechanical properties of poly(L-lactic acid)-poly (ethylene-co-vinyl acetate) blends. Polymer, 40, 2303-2312 (1999).

DOI: $10.1016 / \mathrm{S} 0032-3861(98) 00463-7$

[21] Liu H., Chen F., Liu B., Estep G., Zhang J.: Super toughened poly(lactic acid) ternary blends by simultaneous dynamic vulcanization and interfacial compatibilization. Macromolecules, 43, 6058-6066 (2010). DOI: $10.1021 / \mathrm{ma101108g}$

[22] Liu H., Song W., Chen F., Guo L., Zhang J.: Interaction of microstructure and interfacial adhesion on impact performance of polylactide (PLA) ternary blends. Macromolecules, 44, 1513-1522 (2011). DOI: $10.1021 / \mathrm{ma1} 1026934$

[23] Matonis V. A., Small N. C.: A macroscopic analysis of composites containing layered spherical inclusions. Polymer Engineering and Science, 9, 90-99 (1969). DOI: $10.1002 /$ pen.760090204

[24] Matonis V. A.: The interfacial stresses in particulate composite systems. Polymer Engineering and Science, 9, 100-104 (1969).

DOI: $10.1002 /$ pen.760090205

[25] Jancar J., Dibenedetto A. T.: The mechanical properties of ternary composites of polypropylene with inorganic fillers and elastomer inclusions. Journal of Materials Science, 29, 4651-4658 (1994).

DOI: $10.1007 / \mathrm{BF} 00376292$

[26] Jancar J., Dibenedetto A. T.: Effect of morphology on the behaviour of ternary composites of polypropylene with inorganic fillers and elastomer inclusions. Journal of Materials Science, 30, 1601-1608 (1995). DOI: $10.1007 / \mathrm{BF} 00375271$

[27] Jancar J., Dibenedetto A. T.: Failure mechanics in ternary composites of polypropylene with inorganic fillers and elastomer inclusions. Journal of Materials Science, 30, 2438-2445 (1995). DOI: $10.1007 / \mathrm{BF} 01184598$

[28] Yang H., Zhang X., Qu C., Li B., Zhang L., Zhang Q., Fu Q.: Largely improved toughness of PP/EPDM blends by adding nano- $\mathrm{SiO}_{2}$ particles. Polymer, 48, 860-869 (2007).

DOI: $10.1016 /$ j.polymer.2006.12.022
[29] Yang H., Zhang Q., Guo M., Wang C., Du R., Fu Q.: Study on the phase structures and toughening mechanism in $\mathrm{PP} / \mathrm{EPDM} / \mathrm{SiO}_{2}$ ternary composites. Polymer, 47, 2106-2115 (2006).

DOI: 10.1016/j.polymer.2006.01.076

[30] Chow W. S., Leu Y. Y., Mohd Ishak Z. A.: Effects of SEBS-g-MAH on the properties of injection moulded poly(lactic acid)/nano-calcium carbonate composites. Express Polymer Letters, 6, 503-510 (2012).

DOI: 10.3144/expresspolymlett.2012.53

[31] Gao X., Qu C., Zhang Q., Peng Y., Fu Q.: Brittle-ductile transition and toughening mechanism in POM/TPU/ $\mathrm{CaCO}_{3}$ ternary composites. Macromolecular Materials and Engineering, 289, 41-48 (2004).

DOI: $10.1002 /$ mame.200300222

[32] Premphet K., Horanont P.: Phase structure of ternary polypropylene/elastomer/filler composites: Effect of elastomer polarity. Polymer, 41, 9283-9290 (2000). DOI: $10.1016 / \mathrm{S} 0032-3861(00) 00303-7$

[33] Wu D., Zhang Y., Zhang M., Yu W.: Selective localization of multiwalled carbon nanotubes in poly( $\varepsilon$-caprolactone)/polylactide blend. Biomacromolecules, 10, 417-424 (2009).

DOI: $10.1021 / \mathrm{bm} 801183 \mathrm{f}$

[34] Shi Y. Y., Li Y. L., Wu J., Huang T., Chen C., Peng Y., Wang Y.: Toughening of poly(L-lactide)/multiwalled carbon nanotubes nanocomposite with ethylene-covinyl acetate. Journal of Polymer Science Part B: Polymer Physics, 49, 267-276 (2011).

DOI: $10.1002 /$ polb. 22177

[35] Shi Y. Y., Li Y. L., Xiang F. M., Huang T., Chen C., Peng Y., Wang Y.: Carbon nanotubes induced microstructure and mechanical properties changes in cocontinuous poly(L-lactide)/ethylene-co-vinyl acetate blends. Polymers for Advanced Technologies, 23, 783-790 (2011).

DOI: $\underline{10.1002 / \text { pat.1959 }}$

[36] Li W., Karger-Kocsis J., Schlarb A. K.: Dispersion of $\mathrm{TiO}_{2}$ particles in $\mathrm{PET} / \mathrm{PP} / \mathrm{TiO}_{2}$ and $\mathrm{PET} / \mathrm{PP} / \mathrm{PP}-g-$ $\mathrm{MA} / \mathrm{TiO}_{2}$ composites prepared with different blending procedures. Macromolecular Materials and Engineering, 294, 582-589 (2009).

DOI: $10.1002 /$ mame.200900123

[37] Li W., Karger-Kocsis J., Thomann R.: Compatibilization effect of $\mathrm{TiO}_{2}$ nanoparticles on the phase structure of $\mathrm{PET} / \mathrm{PP} / \mathrm{TiO}_{2}$ nanocomposites. Journal of Polymer Science Part B: Polymer Physics, 47, 1616-1624 (2009).

DOI: $10.1002 /$ polb.21752

[38] Wu S.: Polymer interface and adhesion. Marcel Dekker, New York (1982).

[39] Owens D. K., Wendt R. C.: Estimation of the surface free energy of polymers. Journal of Applied Polymer Science, 13, 1741-1747 (1969). DOI: 10.1002/app.1969.070130815 
[40] Wu D., Sun Y., Lin D., Zhou W., Zhang M., Yuan L.: Selective localization behavior of carbon nanotubes: Effect on transesterification of immiscible polyester blends. Macromolecular Chemistry and Physics, 212, 1700-1709 (2011).

DOI: $10.1002 /$ macp.201100095

[41] Wei J-C., Sun J-R., Wang H-J., Chen X-S., Jing X-B.: Isothermal crystallization behavior and unique banded spherulites of hydroxyapatite/poly(L-lactide) nanocomposites. Chinese Journal of Polymer Science, 28, 499 507 (2010).

DOI: $10.1007 / \mathrm{s} 10118-010-9060-7$

[42] Garlotta D.: A literature review of poly(lactic acid). Journal of Polymers and the Environment, 9, 63-84 (2002).

DOI: 10.1023/A:1020200822435

[43] Hong J. S., Namkung H., Ahn K. H., Lee S. J., Kim C. Y.: The role of organically modified layered silicate in the breakup and coalescence of droplets in PBT/PE blends. Polymer, 47, 3967-3975 (2006).

DOI: $10.1016 /$ j.polymer.2006.03.077

[44] Si M., Araki T., Ade H., Kilcoyne A. L. D., Fisher R., Sokolov J. C., Rafailovich M. H.: Compatibilizing bulk polymer blends by using organoclays. Macromolecules, 39, 4793-4801 (2006).

DOI: $10.1021 / \mathrm{ma} 060125+$

[45] Gubbels F., Jerome R., Teyssie Ph., Vanlathem E., Deltour R., Calderone A., Parente V., Bredas J. L.: Selective localization of carbon black in immiscible polymer blends: A useful tool to design electrical conductive composites. Macromolecules, 27, 1972-1974 (1994). DOI: $10.1021 / \mathrm{ma} 00085 \mathrm{a} 049$

[46] Cai X., Li B., Pan Y., Wu G.: Morphology evolution of immiscible polymer blends as directed by nanoparticle self-agglomeration. Polymer, 53, 259-266 (2012). DOI: $\underline{10.1016 / j . p o l y m e r .2011 .11 .032 ~}$
[47] Bose S., Bhattacharyya A. R., Kodgire P. V., Misra A.: Fractionated crystallization in PA6/ABS blends: Influence of a reactive compatibilizer and multiwall carbon nanotubes. Polymer, 48, 356-362 (2007).

DOI: $10.1016 /$ j.polymer.2006.11.019

[48] Jiang L., Zhang J., Wolcott M. P.: Comparison of polylactide/nano-sized calcium carbonate and polylactide/montmorillonite composites: Reinforcing effects and toughening mechanisms. Polymer, 48, 7632-7644 (2007). DOI: 10.1016/j.polymer.2007.11.001

[49] Kayano Y., Keskkula H., Paul D. R.: Fracture behaviour of some rubber-toughened nylon 6 blends. Polymer, 39, 2835-2845 (1998).

DOI: 10.1016/S0032-3861(97)00600-9

[50] Kim G-M., Michler G. H., Gahleitner M., Fiebig J.: Relationship between morphology and micromechanical toughening mechanisms in modified polypropylenes. Journal of Applied Polymer Science, 60, 13911403 (1996).

DOI: 10.1002/(SICI)1097-4628(19960531)60:9<1391

$$
\because \text { AID-APP15>3.0.CO;2-5 }
$$

[51] Galeski A., Bartczak Z.: Cavitation and cavity-free deformation of filled crystalline polymer systems. Macromolecular Symposia, 194, 47-62 (2003).

DOI: $10.1002 /$ masy.200390105

[52] Balakrishnan S., Start P. R., Raghavan D., Hudson S. D.: The influence of clay and elastomer concentration on the morphology and fracture energy of preformed acrylic rubber dispersed clay filled epoxy nanocomposites. Polymer, 46, 11255-11262 (2005).

DOI: 10.1016/j.polymer.2005.10.053

[53] Bai H., Xiu H., Gao J., Deng H., Zhang Q., Yang M., $\mathrm{Fu}$ Q.: Tailoring impact toughness of poly(Llactide)/poly( $\varepsilon$-caprolactone) (PLLA/PCL) blends by controlling crystallization of PLLA matrix. ACS Applied Materials and Interfaces, 4, 897-905 (2012). DOI: $10.1021 / \mathrm{am} 201564 \mathrm{f}$ 